\title{
POM Beirut 2019 - Politics of the Machines - Art/Conflict
}

The International University of Beirut, Lebanon

11-14 June 2019

Editors:

Morten Søndergaard

Laura Beloff

Hassan Choubassi

Joe Elias 


\section{Abstarct}

In an area afflicted with multifaceted conflicts, art can become an agent for dialogue, an agent for resolution, or it can get itself involved in the clash.

POM Beirut 2019 was a four days of conferences with multiple tracks of paper sessions, panels, workshops, exhibitions, and keynote speakers. The tracks were generated based on a call for topics contextualized under the wide frame of Politics of the Machines, art/conflict. POM Beirut addressed subjects related to art practices in relation to conflicts and questioned several topics on the politics of the machines, and art production in the context of conflicts. It tackles art practices and the relation of art to the machine. In parallel, it also focused on understanding the influence and relation between art and conflict. POM tends to explore the connection between the violence of conflict and violence as a process in art production; the role of conflict in the sociopolitical environment and how it relates to the field of art, science, and technology. 


\section{Full Synopsis}

The 2nd edition of the POM Conference on Art/Conflict, POM Beirut 2019 was hosted by the Institute of Visual Communication (IVC) at the International University (IU) - Beirut campus, Lebanon.

The POM - Politics of The Machines is a conference series founded by Laura Beloff, Aalto University Finland, and Morten Søndergaard, AAU Copenhagen, Denmark.

POM Beirut 2019 was organized by the Institute of Visual Communication IVC under the International University of Beirut, Lebanon.

POM Beirut will comprise four days of conferences with multiple tracks of paper sessions, panels, workshops, exhibitions, and keynote speakers. The tracks will be generated based on a call for topics contextualized under the wide frame of Politics of the Machines, art/conflict. Each track will have several smaller thematic sessions for submission, each chaired by participants selected from the call for topics phase.

Through its suggested tracks, POM Beirut will be addressing subjects related to art practices in relation to conflicts and will be questioning several topics on the politics of the machines, and art production in the context of conflicts.

The goal of this edition of POM will be to tackle art practices and the relation of art to the machine. In parallel, it will also focus on understanding the influence and relation between art and conflict. POM will tend to explore the connection between the violence of conflict and violence as a process in art production; the role of conflict in the sociopolitical environment and how it relates to the field of art, science, and technology.

POM Beirut will also try for a better understanding of the engagement and responsiveness of people and organizations to conflict, exploring how art may serve as a tool for resolution and for social inclusion; or as a counter-argument, a tool for conflict and/or violence. Conflict can also be understood as a contradicting force within an artwork, artistic methods or in a subject matter, it may also push for ethical questions or reveal conflict of interests.

The conference will also encompass few more technical approaches: some tracks may focus on technology employment and conflict, be it armed conflict or conflict provoked by art, the effects of the constant monitoring, surveillance and how we dwell in the panopticon. How today's simulations reflect what is actual and how technology, at this level creates or allows for error, failure and risk. POM will also cover the need to problematize certain aspects of teleworking, telemarketing and tele-surveillance and seek to understand the affinity of technology, violence and power relations. 


\section{Editors}

Morten Søndergaard - Aalborg University, Copenhagen

Laura Beloff - Aalto University Finland

Hassan Choubassi - The International University of Beirut, Lebanon

Joe Elias - The International University of Beirut, Lebanon 


\section{POM Beirut Tracks}

01.Track: Arab revolutions: Refugees, Communication technology, Mobile connectivity. 02.Track: Terrorism machines: Art production, Sociopolitical implications.

03.Track: Fourth Industrial Revolution (IR 4.0): Art, Cyberphysics, Automated creativity. 04.Track: The Battlefield of Vision: Perceptions of War and Wars on Perception.

05.Track: Internet of things: Dystopian Artificial Intelligence, Black Boxes.

06.Track: Living machines: Wars within living organisms.

07.Track: Artificial intelligence for art AIA: Computational creativity, Neural networks, Simulating human activity.

08.Track: Permanent Telesurveillance: Privacy, data protection, panopticon.

09.Track: The Politics of Evidence: Refugees, Frictions, Sound-representation.

10.Track: Body-politics of the machines: Troubles WITH/IN/OUT art, body, perception, politics, and technology.

11.Track: The Ecosystem Analogy: Machinery of Nature, Borrowed landscapes, Anthropology of the near.

\section{Track Details}

01. Arab revolutions:

Refugees, Communication technology, Mobile connectivity.

Track 01 | Chairs Hassan Choubassi, Joe Elias.

The implication of media augmentation within the context of the Arab revolutions, how the image of media augmentation continues to amass the dreads and worries of the modernist when concerned with industrial technologies of production? It exemplifies yet another burden on the masses in the economy, consumption, and psychological manipulation, in dumbing down and in political oppression, until its explosion physically and violently in the Arab world in what is called the "Arab Spring".

02. Terrorism machines:

\section{Art production, Sociopolitical implications.}

Track 02 | Chair Afif Arabi, Zena Meskaoui

The terrorist groups that sprout just after the burst of the revolt of the population in several Arab countries drifted the revolutionary act away from its goals into radical ideologies with specified agendas controlled and manipulated by different international parties that took advantage of the chaos.

\section{Fourth Industrial Revolution (IR 4.0):}

\section{Art, Cyberphysics, Automated creativity.}

Track 03 | Chair Bassam Hussein

New technologies of smart spaces started what is agreed to be called the "Fourth Industrial Revolution" IR 4.0 this has changed ways of lives, work and relationship among people. Because of cyber-physical systems, smart spaces and the Internet of Systems was introduced in industries and workplaces, connect machines and people, visualize chains of production and make autonomous choices. 
04. The Battlefield of Vision:

Perceptions of War and Wars on Perception.

Track 04 | Chair Matt Wraith

The US military strategy of 'Rapid Dominance' summarises its aim as being 'to affect the will, perception, and understanding of the adversary to fight or re... through imposing a regime of Shock and Awe... [to] paralyze or so overload an adversary's perceptions and understanding of events that the enemy would be incapable of resistance...'

05. Internet of things:

Dystopian Artificial Intelligence, Black Boxes.

Track 05 | Chairs Alia Ghaddar, Fadi Yammout, Helena Nikonole.

The Internet of Things (IOT) is increasingly integrated with the daily life real world. It is playing an essential role in the advancement of living spaces from smart buildings to smart cities.

Beyond the current hype, loT is undoubtedly affecting all sectors at a rapid pace: companies, industries, and the economy. This track looks to address the critical role that loT plays in the next generation information and communication systems. The aim is to highlight the opportunities that loT creates for new products, services, and business models and how people harness its potential (creating smarter products, delivering intelligent insights and providing new business outcomes).

0.6 Living machines:

Wars within living organisms.

Track 06 | Chairs Laura Beloff, Nora Vaage, Clarissa Ribeiro.

The idea that living things can be viewed as machines has a long history, stretching back to antiquity. In the 20th century, technological and social developments such as the rise of cybernetics meant biological organisms and the natural environment could be viewed as feedback mechanisms and regulatory systems.

07. Artificial intelligence for art AIA:

Computational creativity, Neural networks, Simulating human activity. Track 07 | Chair Robert B. Lisek.

We observe the success of artificial neural networks in simulating human performance on a number of tasks: such as image recognition, natural language processing, etc. However, There are limits to state-of-the-art Al that separate it from human-like intelligence. Today's Al algorithms are limited in how much previous knowledge they are able to keep through each new training phase and how much they can reuse. In practice, this means that it is necessary to build and adjust new algorithms to every new particular task. This is closer to a sophisticated data processing than to real intelligence. This is why research concerning generalization are becoming increasingly important.

08. Permanent Telesurveillance:

Privacy, Data Protection, Panopticon.

Track 08 | Chairs Mireille Makary, Imad ElZein.

The privacy issue has become so much more evident in the computer age. Computer privacy has become a huge concern as we are increasingly using high tech devices and sharing 
public computers or Internet access points for personal and business purposes. Computer privacy is involved with operating system security, data encryption, access control mechanisms, database protection, network security, and other aspects of protection in computer systems.

\section{The Politics of Evidence:}

\section{Refugees, Frictions, Sound-representation.}

Track 09 | Chairs Morten Søndergaard, Luz Maria Sanchez, Monica Bassbous.

The context of representation is essential when turning data about geopolitical conditions such as the current refugee situation, into a knowledge based on which we can relate to and negotiate that situation. We cannot access or work with pure data as it is, we need a representation of it, for instance, statistic tables, graphics, auditory displays or way of making the data appear to our senses. Data does not exist outside its mediation. Following this line of thought the medium by which data is represented is significant to both our scientific research of data and our scientific understanding of the world as well as to the common public ideas of what data is, or what 'the world' - for instance that of the refugee, departing and traveling - is.

\section{Body-politics of the machines:}

\section{Troubles WITH/IN/OUT art, Body, Perception, Politics, and Technology.} Track 10 - Chairs Ingrid Cogne, Patrícia J. Reis.

Within the cross-disciplinary research field art - science - technology, it has been widely remarked how the proliferation of new technologies affects human and non-human bodies in multiple ways-including perceptually, intellectually, culturally, socially, environmentally, ecologically, ethically, and politically.

\section{The Ecosystem Analogy:} Machinery of Nature, Borrowed landscapes, Anthropology of the near. Track 11 | Chairs Thomas Patrick Pringle, Tarek Mourad, Theo Lepage-Richer. In 1981, Eugene Odum and Bernard Patten argued that "ecosystems are cybernetic." Cybernetics - the informational control of energy_afforded the universal logic of systemic self-regulation that allegedly spanned nature and machines: "Analogy" between biophysical processes and informationally governed technological systems, "and the willingness to accept [analogy], are the keys to identifying the cybernetic machinery of the ecosystem". 


\section{Conference Chairs:}

\section{General Chairs:}

- Morten Søndergaard, Aalborg University, Copenhagen

- Hassan Choubassi, The International University of Beirut, Lebanon

\section{Chairs:}

- Laura Beloff, Aalto University Finland

- Joe Elias, The International University of Beirut, Lebanon

- Sahar Charara, The International University of Beirut, Lebanon

- Tarek Mourad, The International University of Beirut, Lebanon

\section{Thematic Chairs:}

- Afif Arabi

- Zena Meskaoui

- Bassam Hussein

- Matthew Wraith

- Alia Ghaddar

- Fadi Yammout

- Helena Nikonole

- Nora Vaage, Clarissa Ribeiro

- Robert B. Lisek

- Mireille Makary

- Imad El Zein

- Luz Maria Sanchez

- Monica Bassbous

- Ingrid Cogne

- Patrícia J. Reis

- Thomas Patrick Pringle

- Theo Lepage-Richer

\section{Exhibition Chairs:}

- Tarek Mourad

- Hassan Choubassi 


\section{Papers:}

Afif J. Arabi The Thematic and Aesthetic Qualities of ISIS media production http://dx.doi.org/10.14236/ewic/POM19.1

Mustapha M. Hoballah, Zahraa L. Hamoud, Habib M.Awada Electronic Financial Fraud: Abstract, Definitions, Vulnerabilities, Issues and Causes http://dx.doi.org/10.14236/ewic/POM19.2

Konrad Wojnowski War and Dissociation: The Case of Futurist Aesthetics http://dx.doi.org/10.14236/ewic/POM19.3

Jan Løhmann Stephensen Towards a Philosophy of Post-creative Practices? - Reading Obvious' "Portrait of Edmond de Belamy" http://dx.doi.org/10.14236/ewic/POM19.4

Afif Dimitri Haddad Performing Transcendence Through Movement, Perception and Technology http://dx.doi.org/10.14236/ewic/POM19.5

Juan Carlos Duarte Regino Parasitic Radio: combining FM radio signals with environmental sensor data via computing techniques for soundscape creation http://dx.doi.org/10.14236/ewic/POM19.6

Hassan Choubassi, Joe Elias, Tarek Mourad Media Augmentation in the Arab World: The Return of the Repressed http://dx.doi.org/10.14236/ewic/POM19.7

Alia Ghaddar, Mouhamad Hamadani, Fadi Yamout Effects of social media on relationships in Lebanon: A study case for Lebanon http://dx.doi.org/10.14236/ewic/POM19.8

Tarek Mourad Shakkei: the "here", the "there" \& the Selfie http://dx.doi.org/10.14236/ewic/POM19.9

Fadi Yamout, Jenny Issa, Alia Ghaddar Beauty Standards set by Social Media and their Influence on Women's Body Image http://dx.doi.org/10.14236/ewic/POM19.10

Linda Kronman The deception of an infinite view - exploring machine vision in digital art http://dx.doi.org/10.14236/ewic/POM19.11

Karen El Asmar Social Microbial Prosthesis: Towards Super-Organism Centred Design http://dx.doi.org/10.14236/ewic/POM19.12

Rebecca Lee Sanchez Masters of the Screen: On Media Warfare, Optics, and Photography as Fatal Strategy http://dx.doi.org/10.14236/ewic/POM19.13

Kristin Bergaust, Stefano Nichele $\quad$ FeLT-The Futures of Living Technologies http://dx.doi.org/10.14236/ewic/POM19.14

Michelle Christensen, Florian Conradi Hacking Body Politics: Tackling the Technical Tropes http://dx.doi.org/10.14236/ewic/POM19.15

Morten Søndergaard The Politics of Electronic Remembrance. A Brief Study of Deep Media Metaphors - in art and other political lifeforms. http://dx.doi.org/10.14236/ewic/POM19.16

Elmoutasam Aziz, Laila Manasfi The Acoustics of Politics and its Influence on Urban Soundscapes http://dx.doi.org/10.14236/ewic/POM19.17

Mitra Azar Drive to visibility and games of truth: from Panopticon to POV-opticon 
http://dx.doi.org/10.14236/ewic/POM19.18

El-moutasam Aziz, Laila Manasfi, Ghassan Salah A Bio-Political Construction: The Representation of Refugees and Migrants. From the 'Reel' to the 'Real' http://dx.doi.org/10.14236/ewic/POM19.19

Hassan Choubassi, Sahar Sharara

The Body: From Virtual Avatar to Plastic Surgery http://dx.doi.org/10.14236/ewic/POM19.20 